\title{
Diffusion due to fronts in the rotation sub-range of turbulence in the seasonal thermocline
}

\author{
by J. D. Woods \\ University of Southampton (England)
}

\section{1 - Introduction}

The aim of this paper is to reconsider the classical problem of turbulent diffusion in the light of a recent scale analysis of oceanic turbulence, which has shown that the Earth's rotation strongly influences turbulent eddies with vertical scales as small as a few metres. The diffusion problem is to predict the bulk transport rate, expressed as an eddy diffusivity, $K$, on the basis of a theoretical model of the turbulent velocity fluctuations in the sea. Meteorologists call this "parameterization" of the turbulence. Previous attempts at parameterizing turbulence in the ocean (notably by Munk and Anderson, 1948) have assumed that the turbulent motions are not influenced by the Earth's rotation, but only by buoyancy forces (see reviews by Turner, 1972; Bowden, 1964, 1970; Okubo, 1971).

\section{2 - Experimental studies of turbulent transport}

\section{a) Diffusion of dye patches}

Measurements of the diffusion of patches of dye in the upper ocean (reviewed by Okubo, 1971) over periods of up to a month have revealed a number of relationships involving the eddy diffusivity $K$, which must be incorporated into or predicted by diffusion theory. These are summarised in the following list :

1. $K$ increases with the size of the dye patch. This is interpreted as follows:

"The magnitude of $K$ is determined by the turbulent eddies whose dimensions are comparable with the dye patch: eddies much larger than the dye patch advect it but do not enlarge it; eddies much smaller than the dye patch smooth out the inhomogeneities in dye concentration created by the larger ones."

2. The horizontal diffusivity $K_{x}$ is invariably much larger than the vertical diffusivity $K_{z}$.

3. The ratio $K_{x} / K_{z}$ increases with $N$ and $\mathrm{Ri}$.

These conclusions about turbulent diffusion of dye in the upper ocean are supported by diffusion studies in the atmosphere (Pasquill, 1962).

\section{b) The seasonal heating cycle of the upper ocean}

Analysis of long series of bathythermograph from Ocean Weather Station "Papa" and elsewhere have shown that the downward transport of heat inside the seasonal thermocline occurs typically at a monthly average rate for the whole thermocline profile given by $K_{z}=0.3 \mathrm{~cm}^{2} / \mathrm{s}$ (Woods, 1969). While, as Kraus (1972) claims, this may be a relatively unimportant contribution to the seasonal heating cycle of the ocean, it reflects the existence of turbulence inside the seasonal thermocline which may be very important for diffusing tracers other than heat.

\section{c) Vertical diffusion in the deep ocean}

Munk (1966) estimated $K_{z}=1.3 \mathrm{~cm}^{2} / \mathrm{s}$ from measured temperature and salinity profiles in the interior of the Pacific Ocean. Rooth and Ostlund (1972) have calculated $K_{\approx}=0.2 \mathrm{~cm}^{2} / \mathrm{s}$ from the measured distribution of radioactive Tritium that entered the sea as fallout from nuclear bomb tests in the 1950s. The discrepancy between these estimates, which refer to turbulent transports averaged 
over periods of years and the thickness of the main oceanic thermocline, cannot be resolved by one dimensional (i.e. vertical) analysis alone. Nevertheless, the estimates of $K_{z}$ are useful in testing theoretical models of turbulent diffusion.

\section{3 - Scale analysis of turbulence in the ocean}

The starting point for our model of turbulent diffusion is Woods's (1973) scale analysis, which leads to a division of the spectrum of turbulence into a series of ranges (table 1). The principal assumptions underlying this analysis are :

a. The source of turbulent kinetic energy is baroclinic instability at the 1 st mode Rossby radius of deformation, $R=30 \mathrm{~km}$.

b. The cascade of energy from this source to the viscous sink at small scales, while intermittent, is continuous and leads on average to a constant flux of energy $\varepsilon$ through each wavenumber.

c. The value of $\varepsilon$ is equal to that calculated from measurements of the inertial subrange during extended periods of calm weather, when negligible turbulent kinetic energy is assumed to be injected into the cascade from shear instability of internal waves generated by the local wind.

$$
5 \times 10^{-6}<\bar{\varepsilon}<5 \times 10^{-5} \mathrm{erg} / \text { gs. }
$$

\section{Ozmidov length scale}

The first conclusion that we reach from this scale analysis is that overturning motion only occurs in eddies whose vertical (and, since they are essentially isotropic, horizontal) wavelength is given by:

$$
\lambda=\left(\frac{\varepsilon}{N^{3}}\right)^{1 / 2}
$$

This length scale was first proposed by Ozmidov (1965) as being the upper limit of isotropic turbulence. We must clearly associate it with the size of the Kelvin-Helmholtz billows seen in dye photographs in the sea and in clouds in the atmosphere. Billows in the seasonal thermocline have wavelengths of typically 1 metre and this is the Ozmidov length scale for $N=10^{-2} s^{-1}$ and $\varepsilon=10^{-4} \mathrm{erg} / \mathrm{gs}$.

In the turbulent cascade of our model, eddy motions with length scales larger than about a metre will not, therefore, involve overturning.

\section{Rotation range}

The second important conclusion that we reach from this scale analysis is that the rotation threshold, given by:

$$
\lambda_{\text {Rot }}=\left(\frac{\varepsilon}{f^{3}}\right)^{1 / 2}
$$

occurs at mid latitude $\left(f=10^{-4} s^{-1}\right)$ at horizontal wavelengths of 50 metres if we take a mean value of $\bar{\Sigma}=10^{-5} \mathrm{erg} / \mathrm{gs}$ or 200 metres if we take a maximum local value of $\varepsilon^{\prime}=10^{-3} \mathrm{erg} / \mathrm{gs}$.

If we assume that turbulent eddies with horizontal wavelengths larger than this limiting value are approximately in geostrophic equilibrium, then the ratio of the horizontal and vertical wavelengths equals the ratio of $f$ and $N$, thus:

$$
\frac{\lambda_{\text {horizontal }}}{\lambda_{\text {vertical }}}=\frac{\bar{N}}{f}
$$

where $\bar{N}$ is average over $\lambda_{\text {vertical }}$. For the seasonal thermocline we have typically:

$$
N / f \simeq 10^{2}
$$
lence

So for the limiting scale of the rotation range of turbu-

$$
\lambda_{\text {vertical }} \simeq 1 \text { metre }
$$

\section{Implications for diffusion}

Since the rate $K$ of turbulent diffusion depends on the properties of the largest eddies in the diffusing system (e.g. a patch of dye, or the seasonal thermocline) we must start any diffusion theory by comparing the size of the diffusing system with the turbulent ranges derived from scale analysis. It the patch of dye is smaller than one metre across, the rate at which it diffuses will be strongly influenced by the billow turbulence, as I have shown in my diving studies (Woods, 1968). If, on the other hand, the patch of dye has horizontal dimensions of more than about 200 metres, its diffusion will be be controlled by eddies in the rotation range, eddies which we might assume, as a first approximation, to be in geostrophic equilibrium. This is the case for the great majority of dye diffusion studies, described, for example, by Okubo (1971), Kullenberg (1973) and others. And, if we consider the corresponding vertical scales, we conclude that vertical diffusion in the seasonal thermocline on scales greater than a few metres (in the vertical) will be dominated by the rotation range. This includes the monthly average vertical heat flux inside the seasonal thermocline.

\section{4 - Diffusion theory for the rotation subrange}

The aim of diffusion theory is to predict the variation of $K$ with wavenumber $k$ on the basis of some measurable property of the turbulent motions causing the diffusion. Because turbulent motions are by definition irregular, it is inevitable that $K$ theories are statistical, but good $K$ theories avoid introducing statistics for as long as possible. This moral is illustrated below by considering two theories; the first based on the spectrum of horizontal density variance, the second involves detailed consideration of the 
structure of the turbulent eddies controlling the diffusion rate at any particular scale.

\section{5 - Spectral method}

If we assume that turbulent motions in the rotation range are in geostrophic equilibrium, then we can integrate the thermal wind equation to relate the spectrum of horizontal velocity variance $E_{v}(k)$, which cannot easily be measured, to the spectrum of horizontal turbulent density variance $E_{T}(k)$, which can be obtained from the fourier transform of a temperature-salinity probe towed horizontally through the sea, after applying a space-time filter to remove the variance due to internal waves (see Woods, 1973). This leads to the relation (Saunders, 1972)

$$
E_{v}(k)=1 / 2(g / N)^{2} E_{T^{\prime}}(k)
$$

for eddies whose vertical wavelengths are smaller than or equal to the overall system thickness (e.g. the thickness of the seasonal thermocline). If the diffusion rate $K(k)$ is determined by those eddies that lie within a band of width $\delta k$ about the wavenumber $k$, then, on dimensional grounds :

$K(k) \propto g / N\left|\int_{k-\delta k / 2}^{k+\delta k / 2} k^{-2} E_{T^{\prime}}(k) \cdot d k\right|^{1 / 2}-$

The next step is to introduce some physical assumption that will allow us to close the problem by specifying $\delta k$. It is not at all clear to me what the correct assumption should be. But, because we have based the theoretical approach on the density spectrum, any assumption concerning $\delta k$ must be consistent with the way in which $E_{T}(k)$ is measured. This is not a trivial statement, because the distribution of density variance with wavenumber, as derived from the Fourier transform of a record of horizontal density variation $\rho(x)$, is extremely sensitive to the presence of frontal discontinuities in the record. Abrupt steps are an almost universal characteristic of such records and, since the Fourier transform of a sharp step has the form :

$$
E(k) \propto k^{-2}
$$

it is not surprising that the spectra of such records almost invariably have a form close to a -2 power law.

This is clearly the case in Saunders' (1972) sea surface temperature spectra and in Moen's (1974) study of temperature variability in the diurnal thermocline.

Further analysis of the correlation of spectral slope with sharp discontinuities in the original record is currently being carried out in my laboratory at Southampton. Meanwhile, it is clear that (1) will be very sensitive to the presence of frontal discontinuities which will strongly affect the form of $E_{T}(k)$. The physical model needed to close the spectral method must include some statement about the distribution of fronts and hence the probability of including fronts in the record from which $E_{T}(k)$ was calculated. This physical model will be considered in the next sections.

\section{6 - Flow along density surfaces}

Motions responsible for large scale mixing in the ocean are usually assumed to flow mainly along density (or, more strictly, isentropic) surfaces (see for example, Defant, 1961 , p. 105). If the density surfaces are inclined to the horizontal and if there is a concentration gradient of some constituent of seawater (e.g. dye or temperature) along the density surface, the isentropic flow produces both horizontal and vertical transports.

\section{7 - Slope of density surfaces in geostrophic equilibrium}

An expression for the slope of a density surface in geostrophic equilibrium :

$$
S=\frac{d z}{d x}
$$

may be derived from the thermal wind equation:

$$
\begin{aligned}
\frac{d v}{d z} & =\frac{g}{f_{\rho}^{-}} \frac{d p}{d x} \\
& =-\frac{N^{2}}{f} S
\end{aligned}
$$

and the definition of Richardson's number :

$$
\begin{aligned}
\mathrm{Ri} & =\frac{N^{2}}{(\partial v / \partial z)^{2}} \\
& =\frac{f^{2}}{N^{2}} \cdot \frac{1}{S^{2}}
\end{aligned}
$$

whence :

$$
S^{2}=\left(\frac{f}{N}\right)^{2} \cdot \mathrm{Ri}^{-1}
$$

\section{8 - Eddy diffusivity equivalent to motion along density surfaces}

We can define an isentropic eddy diffusivity $K$ for mixing along density (isentropic) surfaces by equating the rate of increase of tracer concentration due to advection along the surface:

$$
\frac{d C}{d t}=U \cdot \frac{d C}{d r}
$$

(where $C$ is the concentration, $d C / d R$ is the concentration gradient along the surface and $U$ is the speed along the surface),

to the rate of increase due to an equivalent diffusivity:

$$
\frac{d C}{d t}=K \frac{d^{2} C}{d r^{2}}
$$


whence :

$$
K=U \cdot \frac{d C / d r}{d^{2} C / d r^{2}}
$$

The equivalent vertical diffusivity will be related to $K$ by the square of the slope:

$$
\begin{aligned}
K_{z} & =W \frac{\partial C}{\partial z} / \frac{\partial^{2} C}{\partial z^{2}} \\
& =U \frac{\partial C}{\partial r} \frac{\partial^{2} C}{\partial r^{2}} \cdot S^{2} \\
& =K / S^{2}
\end{aligned}
$$

Substituting for the slope of geostrophically balanced surfaces obtained in the previous section:

$$
K_{z}=K \cdot\left(\frac{f}{N}\right)^{2} \cdot \mathrm{Ri}^{-1}
$$

and since the slope is usually small $(s<0.01)$ the horizontal diffusivity $K_{x}$ is approximately equal to $K$. Whence the ratio of horizontal to vertical diffusivities is given by:

$$
\frac{K_{i 2}}{K_{z}}=\frac{N^{2}}{f^{2}} \cdot \mathrm{Ri}
$$

\section{9 - The role of fronts}

We now turn our attention to the motion along density surfaces at fronts, where vertical transport reaches a maximum because of the relatively large slope of the density surfaces and the relatively high velocities along them. Hoskins (1971) has shown that these motions at fronts are even more strongly constrained to density surfaces than elsewhere. Furthermore, the surfaces of constant temperature, salinity and other constituents of seawater are generally more strongly inclined to the surfaces of constant density at fronts, which tend to separate water masses having distinct $T-S$ relationships. Finally, fronts are a common feature of small-scale geostrophic turbulence (Charney, 1973, chapter xi) being formed by the deformation field associated with turbulent eddies (Hoskins and Bretherton, 1972). While most of our knowledge of the structure and behaviour of fronts comes from the atmosphere (see, for example, the review by Palmen and Newton, 1969), we have increasing evidence that they occur very commonly in the upper ocean (see, for example, Katz, 1969; Amos, Langseth and Markl, 1972).

These factors, namely the high slopes and velocities, the strong alignment of motion and density surfaces and the strong concentration gradients of constituents of sea water along the density surfaces, lead us to the hypothesis that perhaps we can account for the great majority of diffusion in the upper ocean in terms of motion along density surfaces at fronts. Without further justification, we shall now proceed to parameterize the transport along density surfaces

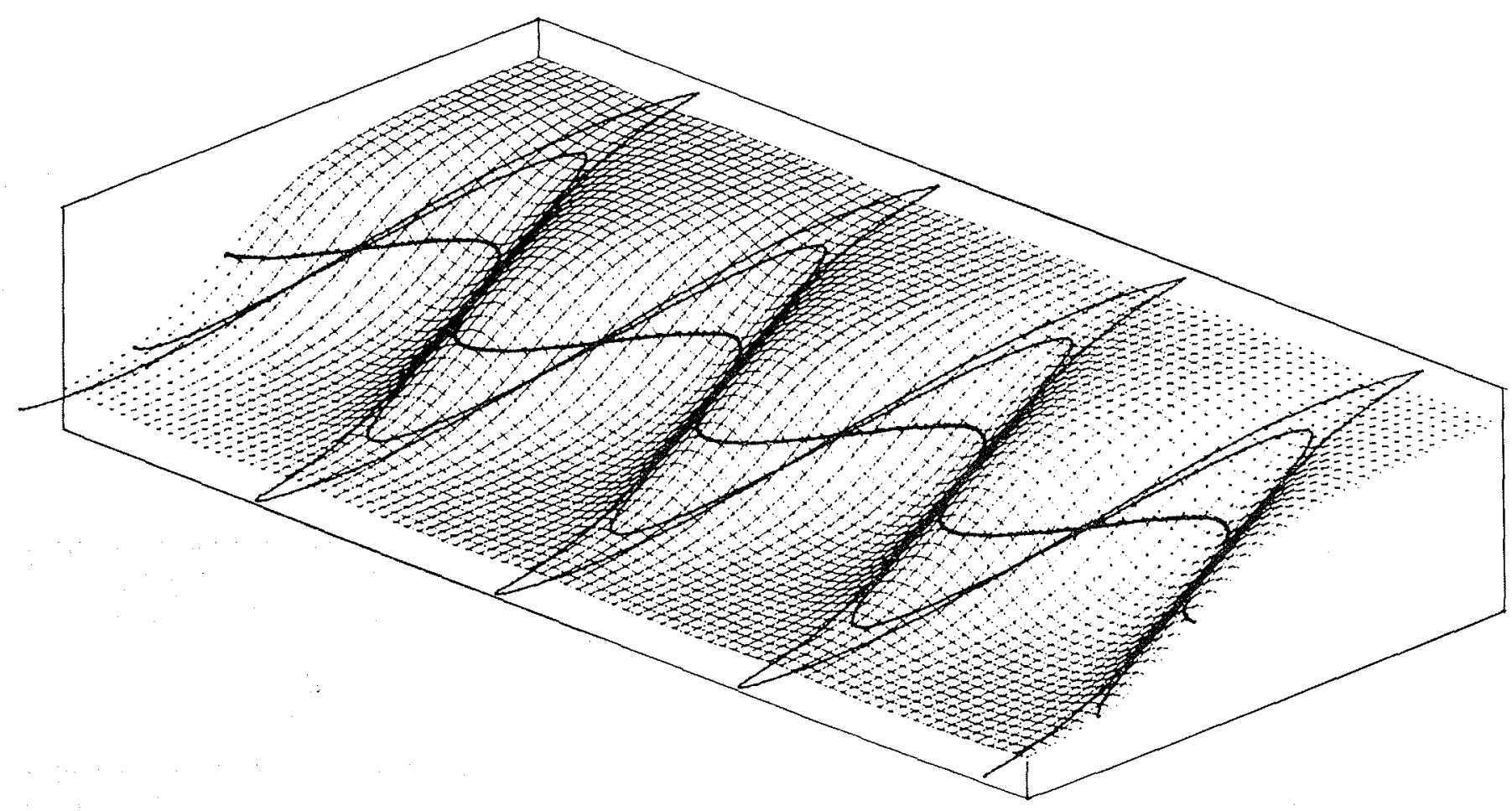

1/ An illustration of water particle trajectories along an isentropic surface inclined to the horizontal at a front, distorted by large amplitude baroclinic waves. The isentropic surface is revealed by the rectangular grid consisting of lines of constant $x$ and $y$. The three bold lines represent hypothetical trajectories along the front with (a) no vertical deviation (b) small and (c) large sinusoidal vertical deviations in phase with the baroclinic wave. 
at fronts in terms of vertical and horizontal eddy diffusivities $K_{z}$ and $K_{x}$.

\section{0 - Motion along density surfaces at fronts}

The description of fronts in this section is based on the results of a four year investigation in the Ionian Sea off Malta by the author (see Woods, 1970 and 1972, for earlier accounts of the structure of fronts in the seasonal thermocline). Evidence from other sources (e.g. Briscoe, Johannessen and Vincenzi, 1974) is less detailed but suggests that the "Maltese" fronts are fairly representative of fronts in rotation range turbulence in the upper ocean. Only those features that are needed to our parameterization will be described here.

In calm weather during summer the seasonal thermocline near Malta outcrops at the sea surface, making it particularly easy to discover the horizontal distribution of temperature in the vicinity of fronts by airborne radiation thermometer (ART) mapping. These maps show that the surface outcrop of the front is disturbed by large amplitude (=4 km) waves of wavelengths typically close to $10 \mathrm{~km}$. These waves have been identified by Orlanski (1968, and private communication) with the fastest growing baroclinic instability on the front. Measurements of the motion of drogues set at a depth of five metres (again in calm weather) show that velocity along the front is typically $12 \mathrm{~cm} / \mathrm{s}$. When we combine this speed with the maximum curvature in the frontal waves, we find that the fronts are strongly ageostrophic, with the curvature term in the momentum equation being comparable with the Coriolis term.

$$
\begin{aligned}
& \text { Curvature term } u^{2} / R=0.9 \times 10^{-3} \mathrm{~cm} / \mathrm{s}^{2} \\
& \text { Coriolis term } \quad f_{u}=1.2 \times 10^{-3} \mathrm{~cm} / \mathrm{s}^{2}
\end{aligned}
$$

The front will therefore be described better by the gradient wind rather than the geostrophic wind relationship.

The strong accelerations produced by curvature will produce a corresponding vertical circulation (Defant, 1961, p. 470). This is seen in vertical temperature sections through the front drawn from series of expendable bathythermographs dropped at $1,2 \mathrm{~km}$ intervals from a Royal Air Force launch moving at 30 knots. Because the contributions from salinity and temperature make opposite contributions to the density gradient at Maltese fronts, both isotherms and isohalines are inclined to the density surfaces. The isotherms and isohalines in sections through the front are, therefore, distorted by the motions along the density surfaces and we can deduce what the motions are from the magnitude of the distortions. In particular, the isotherms are drawn out in tongues running alternately up and down the density surfaces in response to the periodic accelerations produced by the baroclinic waves (fig. 1). The transverse speed $V$ associated with these tongues may be calculated from the observed transverse displacement of the isotherms $\Delta Y$, the quarter wavelength in which this displacement is achieved and the speed $U$ along the front (obtained from drogues).

$$
V=U \frac{\Delta Y}{\lambda / 4}
$$

The corresponding vertical component is given by the vertical displacement $\Delta Z$ of the isotherms

$$
W=U \frac{\Delta Z}{\lambda / 4}
$$

Substituting measured values for the Malta fronts (Woods, 1972), namely $\lambda=10 \mathrm{~km}, U=12 \mathrm{~cm} / \mathrm{s}, \Delta Z=50$ metres and $\Delta Y==8 \mathrm{~km}$, we obtain :

$$
\begin{aligned}
& V=32 \mathrm{~cm} / \mathrm{s} \\
& W=2 \mathrm{~mm} / \mathrm{s}
\end{aligned}
$$

\section{1 - Temperature gradient along density surfaces at fronts}

The vertical component of the temperature profile along the inclined density surface of a front approximates to an exponential curve with about the same scale length as that for the temperature profiles on either side of the front.

$$
T^{\prime}=\Delta T \exp (-\alpha z)
$$

For this curve, the ratio of the first and second differentials of temperature with depth is equal to $1 / \alpha$ :

i.e.

$$
\frac{d T}{d z} / \frac{d^{2} T}{d z^{2}}=\frac{1}{\alpha}
$$

The corresponding ratio for the temperature gradient along the density surface is given by

$$
\frac{d T}{d r} / \frac{d^{2} T}{d r^{2}}=\frac{1}{\alpha S}
$$

and because $S$ is small $(\approx 1 / 100)$ this is very nearly equal to the horizontal component of the same ratio

$$
\frac{d T}{d x} / \frac{d^{2} T}{d x^{2}} \simeq \frac{1}{\alpha S}
$$

\section{2 - Concentration of fronts}

Fronts are assumed to form in the seasonal thermocline in much the same way as they do in the atmospheric troposphere, where (in mid latitudes at least) cyclones almost invariably contain fronts (see for example, Palmén and Newton, 1969). Hoskins and Bretherton (1972) have studied the processes of frontogenesis and Hoskins (private communication) concludes that in this respect the troposphere and seasonal thermocline should be similar $\left(^{a}\right)$. The essential conditions for frontogenesis are (1) a deformation field (2) a sharp gradient of velocity and (3) a density gradient along this vortex sheet. Reports of microstructure in the seasonal thermocline (e.g. Woods and Wiley, 1972) suggest that these conditions are met for eddies in the rotation range of turbulence, which (following Woods, 1974) we associate with the layers that are a

(a) This is currently being checked by $M$. MacVean, a reseatch student in my laboratory at Southampton. 
characteristic feature of the microstructure. Thus we expect frontogenesis to occur in all eddies in the rotation subrange, which have vertical scales from a few metres to the whole thickness of the seasonal thermocline. Fronts may therefore be features of, on the one hand, large cyclones filling the thermocline, with the front running from top to bottom of the thermocline, or, on the other hand, relatively small eddies. Fronts ranging in thickness equal to the whole thermocline down to only one tenth of it have been observed off Malta. It seems reasonable to consider a spectrum of fronts with different dimensions associated with the dimensions of the eddies generating them. If this is the case it is necessary to talk about the concentration of fronts of a given vertical (or horizontal) size. Then following the hypothesis of section 9 above, the rate of diffusion of a patch of dye will depend upon the fronts whose vertical or horizontal extent is comparable with the corresponding dimensions of the dye patch. If, instead of dye diffusion, we are concerned with the mean vertical heat flux inside the seasonal thermocline, taken as a whole, then the fronts that will control the eddy conductivity will be those which extend from top to bottom of the thermocline.

On this model the rate of turbulent diffusion will depend on the concentration of the relevant size of fronts within the diffusing system. We assume that the concentration of fronts is related to the concentration of cyclones formed by baroclinic instability on the corresponding vertical scale. The size of these cyclones is given by the appropriate Rossby radius of deformation $R$ :

$$
\mathrm{R}=\text { Radius of cyclone }=\bar{N} / f \text {. thickness }
$$

Where $\bar{N}=$ Brunt-Väisälä frequency averaged over the same thickness. In the atmosphere cyclones formed in this way do not fill the troposphere; the turbulence is intermittent with an average ratio of order $10 \%$ of the air filled by "first mode" cyclones (i.e. those that extend through the thickness of the troposphere) at any instant. A preliminary assessment of the intermittency of rotation range turbulence in the upper ocean (Moen, 1974) suggests a similar ratio for the seasonal thermocline.

Summarizing, we estimate that the average spacing $\bar{X}$ between neighbouring fronts of a given vertical extent in the seasonal thermocline will be the product of the Rossby radius of deformation for that vertical extent, $R$, and the intermittency factor for the resulting cyclones, $F$.

i.e.

$$
\bar{X}=R \cdot F
$$

For fronts that run from top to bottom of the seasonai thermocline we expect $R \simeq 10 \mathrm{~km}$ and $F \simeq 10 \%$, so

$$
\bar{X}=100 \mathrm{~km}
$$

\section{3 - Parameterization of transport due to fronts}

We are now in a position to parameterize the transport occuring at fronts in the seasonal thermocline. The equivalent diffusivity for a volume of water containing a representative concentration of active fronts of the right size is given by the product of the equivalent diffusivity $K^{\prime}$ for transport by tongues of water running up and down the fronts in response to acceleration produced by baroclinic waves,

$$
\begin{aligned}
K_{z}^{\prime} & =\frac{W}{\alpha} \\
K^{\prime} & =K_{*}^{\prime}\left(\frac{N}{f}\right)^{2} \mathrm{Ri}
\end{aligned}
$$

and the spatial concentration of such tongues, which equals their horizontal thickness divided by their horizontal spacing

$$
C=-\frac{\Delta x}{\bar{X}}
$$

Thus, the mean equivalent eddy diffusivity is given by

$$
\begin{aligned}
& \bar{K}_{z}=\frac{W}{\alpha} \frac{\Delta x}{x_{x}} \\
& \bar{K}_{x}=\bar{K}_{z}\left(\frac{N}{f}\right)^{2} \mathrm{Ri}
\end{aligned}
$$

where the factor $(N / f)^{2}$ Ri refers to the fronts rather than the mean value over large areas.

Substituting measured values for fronts in the seasonal thermocline around Malta,

$$
\begin{aligned}
W & =0.2 \mathrm{~cm} / \mathrm{s} \\
\alpha & =10^{-1} \mathrm{~m}^{-1} \\
(N / f)^{2} \mathrm{Ri} & =4 \times 10^{4} \\
\Delta x & ==1 \mathrm{~km} \\
\bar{X} & =100 \mathrm{~km} \\
\therefore C & =10^{-2}
\end{aligned}
$$

we estimate :

$$
\begin{aligned}
& \bar{K}_{z}=0.2 \times 1,000 \times 0.01=2 \mathrm{~cm}^{2} / \mathrm{s} \\
& \bar{K}_{w}=80,000 \mathrm{~cm}^{2} / \mathrm{s}
\end{aligned}
$$

\section{4 - Discussion}

In attempting to parameterize turbulent transport due to the rotation subrange of turbulence in the seasonal thermocline, we have concentrated on the observed vertical circulation associated with baroclinic waves on fronts in quasi-geostropic eddies. The first estimates, based on observations off Malta, give values of $K_{z} \simeq 0.2 \mathrm{~cm}^{2} / \mathrm{s}$, which are consistent with the observed monthly mean vertical heat flow through the seasonal thermocline. This is encouraging, but our understanding of the structure of rotation range turbulence is still very poor and our model may well have to be revised in the light of new evidence. Nevertheless, I hope that I have shown how we may approach the general problem of explaining diffusion in the upper ocean in terms of turbulence theory. 


\section{Tables}

Classification of turbulence in the seasonal thermocline (after Woods, 1973)

\begin{tabular}{|c|c|c|c|c|c|}
\hline \multirow{2}{*}{ RANGE } & \multirow{2}{*}{ Criterion } & \multirow{2}{*}{ ISOTROPY } & \multicolumn{2}{|c|}{ BOUNDING SCALES } & \multirow{2}{*}{ Characteristic } \\
\hline & & & $\begin{array}{l}\text { Horizontal } \\
\text { Length }\end{array}$ & Time & \\
\hline Viscous & $\operatorname{Re}<1$ & $3 \mathrm{D}$ & \multirow{2}{*}{$\left(\frac{\varepsilon}{v^{3}}\right)^{1 / 4}$} & \multirow{2}{*}{$\left(\frac{\varepsilon}{\nu}\right)^{-1 / 2}$} & \\
\hline \multirow{2}{*}{ Inertial } & $\mathrm{Ri}<1$ & 3D & & & \multirow{2}{*}{ Billow turbulence } \\
\hline & $1 \mathrm{Ne}>1$ & & \multirow{2}{*}{$\left(\frac{\varepsilon}{N^{3}}\right)^{1 / 2}$} & \multirow{2}{*}{$N^{-1}$} & \\
\hline \multirow{2}{*}{ Buoyancy } & $\mathrm{Ri}>1$ & n & & & \\
\hline & Ro $<1$ & & \multirow{2}{*}{$\left(\frac{\varepsilon}{f^{3}}\right)^{1 / 2}$} & \multirow{2}{*}{$f^{-1}$} & \\
\hline \multirow{2}{*}{ Rotation small scale } & Ro $>1$ & \multirow{2}{*}{$2 \mathrm{D}$} & & & $\begin{array}{l}\text { Quasi - geostrophic } E \mathrm{~d} d \text { ie } \mathrm{s} \\
\text { thinner than thermocline }\end{array}$ \\
\hline & & & \multirow{2}{*}{$\frac{N}{f} \cdot H$} & \multirow[t]{2}{*}{$?$} & \multirow{2}{*}{$\begin{array}{l}\text { Eddies fill the thickness of the } \\
\text { thermocline }\end{array}$} \\
\hline Rotation large scale & $\lambda_{v}>2 \lambda \mathrm{H}$ & $2 \mathrm{D}$ & & & \\
\hline Curvature & \multicolumn{2}{|c|}{$f \neq$ const over eddy } & $\varepsilon^{1 / 5} \beta^{3 / 5}$ & $?$ & \\
\hline
\end{tabular}

Coriolis parameter .....F

Brunt-Väisälä frequency. . $N$

Horizontal wavenumber . $k$

Vertical wavenumber $\ldots n=(N / f) k$

Thermal wind equation $. \frac{\partial V}{\partial z} \simeq-\frac{g}{f \bar{\rho}} \frac{\partial \rho}{\partial x}$

Density variance $\ldots \ldots \ldots E_{p}(k)$

Density gradient variance. $k^{2} E_{T}(k)$

Thermocline thickness ...H

Small eddies . . . . . . n $n \geqslant H^{-1} ; k \geqslant(f / N) H$

Kinetic energy ........ $E_{v}(k)=1 / 2(g / N)^{2} E_{T}(k)$

Bandwidth ......... $\delta k$

$$
K(k) \propto\left|\int_{k--\delta k / 2}^{k+\delta k / 2} k-2 E(k) . d k\right|^{1 / 2}
$$

Vertical diffusivity $\ldots \ldots K_{z}(n)=K_{x}(k) .(f / N)^{2}$

\section{OBJECTION}

Most temperature microstructure records show sharp discontinuities.

Fourier transform of a discontinuity has form $E(k) \propto k^{-2}$. Most temperature microstructure spectra have this form.

Measured values of $E_{q^{\prime}}(k)$ are usually not true local values of horizontal density variance concentration, but they reflect the fourier transform of frontal discontinuities included in the sample.
Coriolis parameter ..... $f$

Brunt-Väisälä frequency.. $\quad N=\left(\frac{g}{\bar{\rho}} \frac{d p}{\partial z}\right)^{1 / 2}$

Slope of density surface . $\quad S=\frac{d z}{d x}$

Thermal wind equation $. . \frac{d v}{d z}=-\frac{g}{f \rho} \frac{d \rho}{d x}$

$$
=\frac{-N^{2}}{f} \cdot S
$$

Richardson number $\ldots . \quad R \mathbf{R}=\frac{N^{2}}{(\partial v / \partial z)^{2}}$

$$
=\frac{f^{2}}{N^{2}} \frac{1}{S^{2}}
$$

$$
S^{2}=\left(\frac{f}{N}\right)^{2} \cdot \mathrm{Ri}^{-1}
$$


Temperature profile $\ldots . \quad T=T_{0} \exp (-\alpha z)$

$$
\therefore \alpha=\left(\partial^{2} T / \partial z^{2}\right) /(\partial T / \partial z)
$$

Slope of density surface .. $\quad S=\frac{\partial z}{\partial x}=(f / \mathrm{N}) \mathrm{Ri}^{-1 / 2}$

Temperature gradient $\ldots \quad \frac{\partial T}{\partial r}=\frac{\partial T}{\partial z} \cdot \frac{\partial z}{\partial x}=S \frac{\partial T}{\partial z}$

Velocity along surface .. $U=\frac{\partial z}{\partial t} \cdot \frac{\partial x}{\partial z}=W / s$

Rate of temperature rise $\cdot \frac{d T}{d t}=U \frac{\partial T}{\partial r}=W \frac{\partial T}{\partial z}$

Equivalent diffusivity $\ldots \quad \frac{d T}{d t}=K_{z} \frac{\partial^{2} T}{\partial z^{2}}=K_{r} \frac{\partial^{2} T}{\partial r^{2}}$

Substituting

$$
K_{z}=W \frac{\partial T}{\partial z} / \frac{\partial^{2} T}{\partial z^{2}} \frac{W}{\alpha}
$$$$
K_{r}=U \frac{\partial T}{\partial r} / \frac{\partial^{2} T}{\partial r^{2}}
$$$$
=\frac{W}{\alpha S^{2}}=K_{z^{2}} / S^{2}
$$

$$
\therefore \frac{K x}{K z}=\frac{1}{S^{2}}=\left(N^{2} / f^{2}\right) . \mathrm{Ri}
$$

\section{5}

Waves on fronts

Scale length of thermocline $\ldots .1 / \alpha \simeq 15$ metres

Mean static stability

$$
\bar{N}=10^{2} s^{-1}
$$

Coriolis parameter

$f=10^{-4} s^{-1}$

Rossby radius of deformation . . R $=1.5 \mathrm{~km}$

Wavelength of instability on front $\quad \lambda_{i}=2 R=9.5 \mathrm{~km}$

Observed wavelength $\ldots \ldots \ldots \quad \lambda=10 \mathrm{~km}$

Observed peak-peak amplitude . $2 a=4 \mathrm{~km}$

Observed particle velocity along front $\ldots \ldots \ldots \ldots \ldots \ldots . u=12 \mathrm{~cm} / \mathrm{s}$

Gradient wind equation :

Coriolis term $\ldots \ldots \ldots \ldots f u=1.2 \times 10^{-3} \mathrm{~cm} / \mathrm{s}^{2}$

Curvature term $\ldots \ldots \ldots u^{2} / R=0.96 \times 10^{-3} \mathrm{~cm} / \mathrm{s}^{2}$
Parameterization of isentropic advection at fronts

Observed properties:

Thickness of thermocline ... $H=100 \mathrm{~m}$

Mean Brunt-Väisälä frequency $N=10^{-2} s^{-1}$

Coriolis parameter $\ldots \ldots \ldots f f=10^{-4} s^{-1}$

Rossby radius of deformation. $R=N / f . H=10 \mathrm{~km}$

Temperature profile $\ldots \ldots \ldots 1 / \alpha \simeq 10 \mathrm{~m}$

At fronts :

Richardson number $\ldots \ldots \ldots, \overline{\mathrm{Ri}} \simeq 2$

Slope of isentropic surfaces .. $s \simeq 1 / 200$

Wavelength $\ldots \ldots \ldots \ldots \ldots \quad \lambda \simeq 10 \mathrm{~km}$

Velocity of water particles along front $\ldots \ldots \ldots \ldots \ldots u=10 \mathrm{~cm} / \mathrm{s}$

Vertical displacement of tongues $\ldots \ldots \ldots \ldots \ldots \ldots . \Delta z=50 \mathrm{~m}$

Halfwidth of tongues $\ldots . . \Delta y=\lambda / 4$

Thickness of tongues $\ldots \ldots . \delta=10 \mathrm{~m}$

\section{Hence:}

1. Vertical speed of water particles in tongues ........ $w=u \cdot \frac{\Delta z}{\Delta y}=2 \mathrm{~mm} / \mathrm{s}$

2. Concentration of frontal lobes $\ldots \ldots \ldots \ldots \ldots \ldots \ldots, c \leqslant(\delta / s) / 2 R$

$$
\simeq 1 / 60
$$

Equivalent eddy diffusivities :

$$
\begin{aligned}
& K_{z}=(w / \alpha) \cdot c=3.3 \mathrm{~cm} / \mathrm{s} \\
& K_{z}=K_{z} \cdot(N / f)^{2} \cdot \mathrm{Ri}=1.3 \times 10^{4} \mathrm{~cm}^{2} / \mathrm{s}
\end{aligned}
$$




\section{References}

Amos (A. F.), Langseth (M. G.) and Markl (R. G.). - Visible saline fronts, in «Studies in Physical Oceanography». Vol. I (1972). Edit. by A.L. Gordon, Gordon and Breach, New York.

Bowden (K. F.). - Turbulence (1964). Oceanogr. Mar. Biol, Ann. Rev. 2 : 11-30.

BOWDEN (K. F.). -- Turbulence II (1970). Ibid $8:$ 11-32.

Briscoe (M. G.), Johannessen (O. M.) and Vicenzi (S.). - The Maltese oceanic front: a surface description by ship and aircraft (1974). Deep Sea Res. 21, 247-262.

Charney (J.G.). - Planetary Fluid Dynamics, in «Dynamical Meteorology 》 (1973). Ed. by P. Morel, Reidel, Dordrecht and Boston.

Defant (A.). - Physical Oceanography, Vol. I (1961). Pergamon, London.

Hoskins (B. J.). - Atmospheric frontogenesis : some solutions (1971). Q.J. Roy. Met. Soc., $97: 139-153$.

Hoskins (B. J.) and Bretherton (F. P.). - Atmospheric frontogenesis: Mathematical formulation and solution (1972). J. Atmor. Sci., $29: 11-37$.

KATZ (E.). - Further study of a front in the Sargasso Sea (1969). Tellus, 21 (2) : 259-269.

Kraus (E. B.). - «Ocean Atmosphere Interaction» (1972). Oxford.

Kullenberg (G.). - Diffusion in stratified vertical shear flow (1973). Memoires Soc. Roy. Sci. Liège, 6 ${ }^{\mathrm{c}}$ série, $4: 41-45$.

MOEN (J.). - The spectrum of horizontal variability of sea surface temperature (1974). M. Sc. dissertation, Univ. Southampton (England).

Munk (W. H.). - Abyssal recipes (1966). Deep-Sea Res., 13 : 707-730.

Munk (W. H.) and ANderson (E. R.). - Note on a theory of the thermocline (1948). J. Mar. Res., $7: 276-295$.
OKuBo (A.). - Horizontal and vertical mixing in the sea, Chapter 4 in «The impingement of Man on the Oceans》 (1971). Ed. by D.W. Hood, Wiley (1971).

OrLANSKI (I.). - Instability of frontal waves (1968). J. Atmos. Sci. $25: 178-200$.

Ozmidov (R. V.). - On turbulent exchange in a stably stratified ocean (1965). Atmos. and Oceanic Phys., 1 (8): 493-497.

PALMÉN and NEWTON. - «The structure of atmospheric circulations systems 》 (1969). Academic Press, London.

Pasquill (F.). - "Atmospheric Diffusion» (1962). Van Nostrand. London.

Rooth (C. G.) and Ostlund (H. G.). - Penetration of tritium into the Atlantic thermodine (1972). Deep Sea Res., 19:481-492.

SAUNders (P.R.). - Space-time variability of temperature in the upper ocean (1972). Deep-Sea Res., $19: 467-480$.

Turner (J.S.). - «Buoyancy effects in fluids» (1972). Cambridge Univ. Press.

Woods (J.D.). - Wave induced shear instability in the summer thermocline » (1968). J. Fluid Mech., 32: 791-800.

Woods (J. D.). - Micro-oceanographical studies in the summer thermocline around Malta (1969). MRCP 241 Met. Office, England,

Woods (J. D.). - Measuring thermocline fronts from the air (1970) Underwater J., 2 : 90-99.

Woods (J.D.). - The structure of fronts in the seasonal thermocline (1972). Proc. Conf. "Strait of Sicily», Saclantcen, La Spezia.

Woods (J. D.). - Space-time characteristics of turbutence in the seasonal thermocline (1973). Mem. Soc. Roy. Sci., Liège, $6^{\text {c }}$ série, tome VI, $109-130$.

Woons (J.D.) and WILEY (R. L.). - Billow turbulence and ocean microstructure (1972). Deep-Sea Res., $19: 87-121$. 


\section{Discussion}

Président : M. J. DUPORT

M. le Président remercie chaleureusement M. le Professeur Woods pour son exposé et pour son film, qui ouvrent de nouveaux horizons sur la génèse et l'évolution des thermoclines.

Il ouvre ensuite la discussion.

M. Hopfinger pose (en anglais) au Professeur Woods, les questions suivantes :

Dans une thermocline à la mer, après la naissance d'une instabilité et la formation de la turbulence, on observe deux nouvelles couches à fort gradient.

En Laboratoire, au contraire, le gradient de densité reste continu (voir schémas ci-dessous) après que la croissance de la couche turbulente cesse et même après que cette couche s'est évanouie (Thorpe 1971, J.F.M.) ; j'ai aussi observé ceci dans mes propres expériences). En laboratoire, la couche turbulente croît jusqu'à ce qu'un nombre de Richardson critique soit atteint (Ric $\cong 0,3$ ); après, il n'existe désormais aucun des processus de mélange qui seraient nécessaires pour assurer la poursuite de l'homogénéisation de la densité dans la couche.

Dans ces conditions, comment expliquez-vous la nouvelle formation de thermocline dans l'océan? Est-il nécessaire d'avoir une hétérogénéité horizontale?

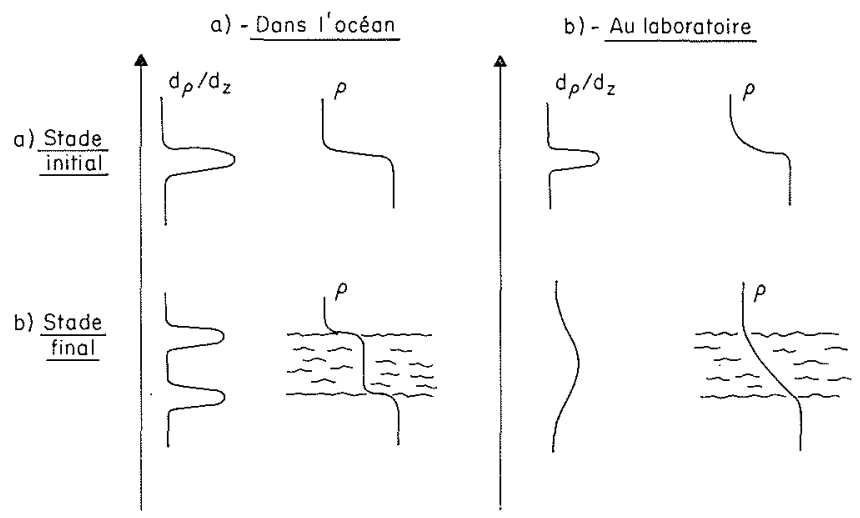

\section{RÉPONSE DE M. WOODS :}

M. HopfINGER's question is concemed with the small scale turbulence formed by wave-induced shear instability at Richardson number less than 1/4. As shown in table 1 of my paper, this transition occurs at a vertical scale of less than one metre. Using flow vizualization techniques (Woods, 1968) one can associate this transition with the formation of Kelvin-Helmoltz billows, whose heights are typically about $20 \mathrm{~cm}$ in the seasonal thermocline. Woods and Wiley (1972) have reported ihat after swch a patch of small scale turbulence formed in the sea has decayed (i.e. when the turbulent velocity fluctuations have stopped) there remains significant temperature (density) microstructure on a scale of about $10 \mathrm{~cm}$. Thorpe (1971), on the other hand, observing similar billow turbulence in the laboratory, finds that, when it has decayed, there remains very little density microstructure on the scale of the billows. $A$ number of differences between the laboratory and oceanic conditions may contribute to these observed different end results. Firstly, Thorpe's billows have Reynolds numbers of a few thousands, an order of magnitude larger than those in the seasonal thermocline. Thus viscosity acts directly to attenuate the turbulent kinetic energy on scales approaching that of the billows, and the turbulence has a tendency to decay at rather an earlier stage that in the laboratory, leaving the mixing less complete. Secondly, and perhaps more importantly, billow turbulence in the sea is provoked by internal gravity waves which contribute approximately half of the shear needed reduce the Richardson number below 1/4. Observations of these waves shows (Woods, 1968) that their period is comparable with the lifetime of the turbulence event. Thus, although the waves cause the billows to develop in the first place, when they pass through the billow's by half a wavelength, their contribution to the shear reverses and the Richardson number rises rapidly, causing the turbulence to be prematurely quenched, and leaving a partially mixed region with significant microstructure on the scale of the billows. Thirdly, we have the possibility mentionned by M. HopFINGER, namely the existence of horizontal density gradients. While acknowledging that these surely exist, I suspect that this effect is less significant in generating microstuclure than the first two effects. I should perhaps point out that while these small scale mixing events do not form the central theme of the paper I presented today, they play a crucial role in mixing into their surroundings the tongues of cold water carried upwards along the surface of fronts (and equally the wam tongues carried downwards). Without such small scale mixing the large scale, advective processes would not produce an irreversible heat transport.

Personne ne demandant plus à intervenir, M. le Président clôt la discussion. 